\title{
An analysis of the performance of Black African junior provincial cricket batsmen
}

\author{
Mogammad Sharhidd Taliep (PhD) \\ Raeeq Gamieldien (BTech) \\ Sacha Jane West (PhD) \\ Cape Peninsula University of Technology, Department of Sports Management
}

Correspondence to: Mogammad Taliep (talieps@cput.ac.za)

\begin{abstract}
Objectives. This study investigated the difference in performance of white $(\mathrm{W})$, coloured/Indian (C/I) and black African (BA) cricket batsmen at a junior provincial level in South Africa over a period of 7 years.

Methods. Data of all players participating in the South African interprovincial under-15 (U15) and under-19 (U19) tournaments between the years 2004 and 2010 were analysed. The number of participants, batting averages and number of batsmen in the top 20 run scorers in the tournament were compared between groups.

Results. $52 \%$ of players were white and $48 \%$ were black $(27 \%$ $\mathrm{BA}$ and $21 \% \mathrm{C} / \mathrm{l})$. BA batting averages (runs/dismissal) were significantly $(p<0.05)$ lower than W batting averages for every year from 2004 to 2010 for both the U15 and U19s. W batsmen only had significantly better batting averages than $\mathrm{C} / \mathrm{l}$ for the $\mathrm{U} / 15 \mathrm{~s}$ in 2010 and for the U19s in 2009 and 2010. W batsmen dominated the top 20 run scorers in the tournament in each year for both U15s and U19s while there were few BA batsmen represented in the top 20.

Conclusion. The performances of BA batsmen at junior provincial level are well below those of $\mathrm{W}$ batsmen and appear to follow the same trend as the senior provincial batsmen.
\end{abstract}

\section{Introduction}

As a consequence of apartheid, racial categorisation is common in South African sport. To understand the progression of cricketers who have been previously disadvantaged because of apartheid, it is necessary to racially classify players. Cricketers in this study were categorised as white (W), black African (BA) or coloured/Indian (C/I). ${ }^{1}$ Whenever the category 'black' is mentioned alone, it refers to $\mathrm{C} / \mathrm{I}$ and B/A.

After apartheid, the South African government and Cricket South Africa (CSA) introduced a number of development and transformation policies to try and amend the injustices of the past. ${ }^{2-4}$ Consequently, an enormous amount of money was spent on the development of facilities, coaching, administration and cricketing skills of previously disadvantaged communities in an attempt to increase participation and facilitate cricketing excellence within the black communities. ${ }^{3}$ The promotion of a Mini Cricket programme has been successful in introducing over 2 million young children to softball cricket in South Africa. ${ }^{5}$ Transformation targets were also introduced as part of the transformation policy. Currently, CSA subscribes to targeted transformation set for all representative cricket. Senior provincial teams have a target of 4 black players in a team of 11 players while junior provincial teams have a target of 6 black players in a 12-player squad.

The development and transformation policies are aimed at increasing black representation and performance at all levels of cricket. ${ }^{4}$ The effectiveness of the cricket transformation process with regard to increasing representation and performance of black cricketers at senior provincial level in South Africa has previously been investigated. ${ }^{1}$ It was found that these processes were effective in increasing participation of senior black provincial players between 1996 and 2008. There were no significant differences in the bowling performance between BA and W bowlers between the 2000/2001 and 2007/2008 seasons. This can be seen as a success of the transformation process in producing skilled BA bowlers. However, there were few skilled BA batsmen participating in senior provincial cricket. Furthermore the performance of the BA batsmen was significantly worse than the $\mathrm{W}$ batsmen in every season between 2000 and 2008. The number and performance of BA batsmen at senior provincial level is thus a concern. If it is assumed that the junior provincial batsmen are a feeder for the senior provincial batsmen then investigating the participation and performance of junior batsmen is imperative. It has also been suggested that BA players were performing at junior provincial level but have not been afforded the opportunity in the senior teams and consequently do not feature in the senior provincial teams. ${ }^{6}$ Therefore, the aim of this study was to investigate the performance of BA batsmen at junior provincial level (U15 and U19) between 2004 and 2010, and establish whether they follow the same trend as the senior provincial players. The results of this study could impact CSA's future development and transformation policies.

\section{Methods}

All data were taken from the U15 and U19 annual interprovincial cricket tournaments in South Africa between 2004 and 2010. Only $2 \%$ of all South African players were not racially classified due to insufficient information on those players and they were therefore excluded from all analyses. Data of the 2005 U15 interprovincial tournament were also not available and excluded from the analysis. Linear regression analysis was used to compare the percentage change in the number of players (separated according to their different racial groups) participating each year. A non-parametric independent sample (Kruskal-Wallis) test was used to determine the difference between the median batting averages (runs/dismissal) of the different racial groups for each year. Linear regression analysis was used to compare the change in the median batting average between 2004 
and 2010 . The top 20 run scorers for each year were also recorded and compared to par representation for each group. Par representation was determined by calculating the percentage representation of each group relative to their total representation in that year. The following equation was used to calculate par representation:

$$
\begin{aligned}
& \text { Par representation }(x, y, z)=(\text { Total percentage } \\
& \text { participation } x 20) / 100 .
\end{aligned}
$$

Where $x, y, z$ represent $W, C / I$ and $B A$ respectively.

The par value was then subtracted from the actual representation of the group in the top 20 and plotted. Therefore a value of 1 indicates that a group had 1 person more than the estimated par value for that group, a value of -1 indicates that a person has 1 person less than the estimated par value for that group.

\section{Results}

The percentage of players participating in the U15 and U19 tournament is represented in Table I. There appears to be relatively equal representation in the $\mathrm{U} 15$ and $\mathrm{U} 19$ interprovincial tournaments for the W (approximately 50\%) and black players (approximately 50\%) for each year. Linear regression analysis indicates that there was a significant decrease in the percentage of BA players between 2004 and 2010 for both the U15s $\left(r=-0.88 r^{2}=0.779, p=0.020\right)$ and U19s $\left(r=-0.98 r^{2}=0.96, p<0.000\right)$. There was a significant increase in the percentage of $\mathrm{C} / \mathrm{l}$ players participating in both the $\mathrm{U} 15(\mathrm{r}=0.90$, $\left.r^{2}=0.802, p=0.016\right)$ and $\mathrm{U} 19\left(r=0.90, r^{2}=0.81, p=0.006\right)$ group but no significant change in the percentage of $\mathrm{W}$ players participating in the both the U15 $\left(r=0.36, r^{2}=0.13, p=0.478\right)$ and $U 19\left(r=0.69, r^{2}=0.48\right.$,

\begin{tabular}{|c|c|c|c|c|}
\hline Year & $\mathrm{W} \%(N)$ & $\mathrm{C} / \mathrm{l} \%(N)$ & BA \% (N) & Total $^{*} \%(N)$ \\
\hline \multicolumn{5}{|l|}{ U15 } \\
\hline 2004 & $50(95)$ & $21(39)$ & $30(56)$ & $100(190)$ \\
\hline 2005 & - & - & - & - \\
\hline 2006 & $52(104)$ & $20(40)$ & $29(58)$ & $100(202)$ \\
\hline 2007 & $51(102)$ & $22(44)$ & $28(56)$ & $100(202)$ \\
\hline 2008 & $53(100)$ & $24(46)$ & $23(43)$ & 100 (189) \\
\hline 2009 & $50(99)$ & $25(50)$ & $24(48)$ & $100(197)$ \\
\hline 2010 & 52 (102) & $25(50)$ & $23(46)$ & $100(198)$ \\
\hline \multicolumn{5}{|l|}{ U19 } \\
\hline 2004 & $51.0(101)$ & $15.7(31)$ & $33.3(66)$ & $100.0(198)$ \\
\hline 2005 & $47.6(88)$ & $21.6(40)$ & $30.8(57)$ & $100.0(185)$ \\
\hline 2006 & $49.3(99)$ & $19.9(40)$ & $30.8(62)$ & $100.0(201)$ \\
\hline 2007 & $54.0(107)$ & $20.2(40)$ & $25.8(51)$ & $100.0(198)$ \\
\hline 2008 & $52.0(105)$ & $24.3(49)$ & $23.8(48)$ & $100.0(202)$ \\
\hline 2009 & 52.7 (109) & $25.6(53)$ & $21.7(45)$ & $100.0(207)$ \\
\hline 2010 & $53.7(102)$ & $25.8(49)$ & $20.5(39)$ & $100.0(190)$ \\
\hline
\end{tabular}
$p=0.086$ ) tournament between 2004 and 2010 .
A comparison of the batting average between the racial groups for the U15 and U19s are represented in Tables II and III, respectively. For the U15s the BA batsmen had significantly lower batting averages than W batsmen in every year between 2004 and 2010 (Table II). There was no significant difference in the batting average between $\mathrm{W}$ batsmen and C/I batsmen for the U15s except in 2010, where $\mathrm{W}$ batsmen had significantly higher batting averages. There were also no significant differences in the batting average of $\mathrm{C} / \mathrm{l}$ and B/A batsmen for the U15s except for 2007 , where $\mathrm{C} / \mathrm{l}$ batting average was significantly better. For the U19s, BA batsmen had significantly lower batting averages than W batsmen in every year between 2004 and 2010 (Table III). There was no significant difference in the batting average between W batsmen and C/I batsmen except in 2009 and 2010, where $\mathrm{W}$ batsmen had significantly higher batting averages (Table III). There were also no significant differences in the batting average of $\mathrm{C} / \mathrm{l}$ and BA batsmen except for 2006, where $\mathrm{C} / \mathrm{l}$ batting average was significantly better. Linear regression analysis indicates that there was an improvement in the batting average of BA between 2004 and 2010 for the U19s (Fig. 1). There was no significant improvement in batting average for any of the other racial groups.

TABLE II. A comparison of the U15 batting averages of the different racial groups between the

\begin{tabular}{|c|c|c|c|}
\hline Year & Race & $\begin{array}{l}\text { Batting average } \\
\text { (runs/dismissal) }\end{array}$ & $p$-value \\
\hline \multirow[t]{3}{*}{2004} & W v. C/I & 17.6 v. 11.0 & 0.135 \\
\hline & W v. BA & 17.6 v. 6.3 & $0.000^{*}$ \\
\hline & C/I v. BA & 11.0 v. 6.3 & 0.100 \\
\hline \multirow[t]{3}{*}{2006} & W v. C/I & 18.3 v. 12.7 & 0.229 \\
\hline & W v. BA & 18.3 v. 9.8 & $0.001^{*}$ \\
\hline & C/I v. BA & 12.7 v. 9.8 & 0.688 \\
\hline \multirow[t]{3}{*}{2007} & W v. C/I & 16.0 v. 13.2 & 0.885 \\
\hline & W v. BA & 16.0 v. 6.2 & $0.000^{*}$ \\
\hline & C/I v. BA & 13.2 v. 6.2 & $0.008^{*}$ \\
\hline \multirow[t]{3}{*}{2008} & W v. C/I & 13.5 v. 9.7 & 0.196 \\
\hline & W v. BA & 13.5 v. 6.5 & $0.000^{*}$ \\
\hline & C/I v. BA & 9.7 v. 6.5 & 0.221 \\
\hline \multirow[t]{3}{*}{2009} & W v. C/l & 17.8 v. 11.3 & 0.067 \\
\hline & W v. BA & 17.8 v. 7.4 & $0.000^{*}$ \\
\hline & C/I v. BA & 11.3 v. 7.4 & 0.058 \\
\hline \multirow[t]{3}{*}{2010} & W v. C/I & 26.9 v. 21.4 & $0.034^{*}$ \\
\hline & W v. BA & 26.9 v. 7.2 & $0.000^{*}$ \\
\hline & C/I v. BA & 21.4 v. 7.2 & 0.422 \\
\hline
\end{tabular}
2004 and 2010

Data of the top 20 players who scored the most runs in the interprovincial tournament for each year are represented in Table IV. In the U15 group there were only two BA batsmen in the top 20 run scorers in 2004 and 2006 and one in 2007. More recently, in 2008, 2009 and 2010 there were no BA batsmen representative in the top 20 for the U15s. Similarly, there are few BA batsmen in the top 20 in the U19 between 2004 and 2010. 


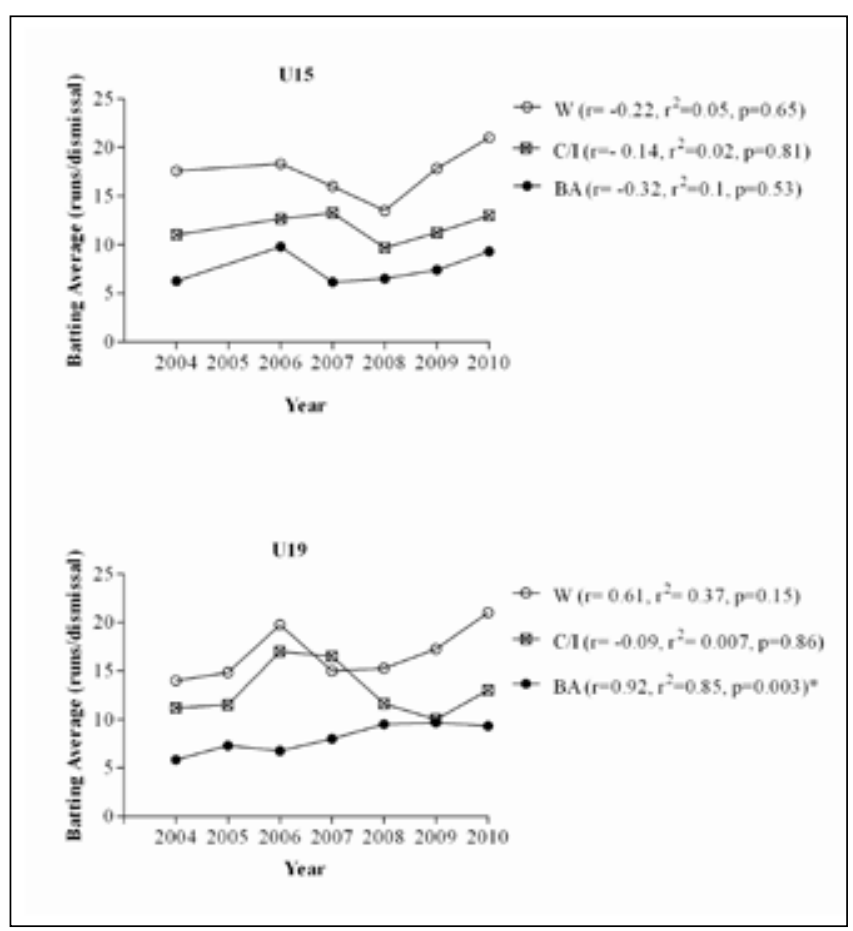

Fig. 1. Regression analysis of the batting averages for the U15s and U19s between 2004 and 2010. Significant difference $(p<0.05)$ represented by *

TABLE III. A comparison of the U19 batting averages of the different racial groups between the 2004 and 2010

\begin{tabular}{|c|c|c|c|}
\hline Year & Race & $\begin{array}{l}\text { Batting average } \\
\text { (runs/dismissal) }\end{array}$ & $p$-value \\
\hline \multirow[t]{3}{*}{2004} & W v. C/l & 14.1 v. 11.2 & 0.524 \\
\hline & W v. BA & 14.1 v. 5.8 & $0.000^{*}$ \\
\hline & C/I v. BA & 11.2 v. 5.8 & 0.208 \\
\hline \multirow[t]{3}{*}{2005} & W v. C/l & 14.8 v. 11.5 & 0.116 \\
\hline & W v. BA & 14.8 v. 7.3 & $0.000^{*}$ \\
\hline & C/I v. BA & 11.5 v. 7.3 & 0.404 \\
\hline \multirow[t]{3}{*}{2006} & W v. C/l & 14.8 v. 11.5 & 0.377 \\
\hline & W v. BA & 14.8 v. 7.3 & $0.000^{*}$ \\
\hline & C/I v. BA & 11.5 v. 7.3 & $0.002^{*}$ \\
\hline \multirow[t]{3}{*}{2007} & W v. C/I & 15.0 v. 16.5 & 1.000 \\
\hline & W v. BA & 15.0 v. 8.0 & $0.001^{*}$ \\
\hline & C/l v. BA & 16.5 v. 8.0 & 0.078 \\
\hline \multirow[t]{3}{*}{2008} & W v. C/I & 15.3 v. 11.6 & 1.000 \\
\hline & W v. BA & 15.3 v. 9.5 & $0.014^{*}$ \\
\hline & C/I v. BA & 11.6 v. 9.5 & 0.272 \\
\hline \multirow[t]{3}{*}{2009} & W v. C/I & 17.3 v. 10.0 & $0.015^{*}$ \\
\hline & W v. BA & 17.3 v. 9.7 & $0.002^{*}$ \\
\hline & C/I v. BA & 10.0 v. 9.7 & 1.000 \\
\hline \multirow[t]{3}{*}{2010} & W v. C/I & 21.0 v. 13.0 & $0.034^{*}$ \\
\hline & W v. BA & 21.0 v. 9.3 & $0.000^{*}$ \\
\hline & C/I v. BA & 13.0 v. 9.3 & 0.422 \\
\hline *Signific & nce $(p<0.05)$. & & \\
\hline
\end{tabular}

TABLE IV. Number of players in the top 20 run scorers in the interprovincial U15 and U19 tournaments between 2004 and 2010

\begin{tabular}{llll}
\hline Year & W $(\boldsymbol{N})$ & $\mathbf{C} / \mathbf{( N )}$ & BA $(\boldsymbol{N})$ \\
\hline U15 & & & \\
2004 & 14 & 4 & 2 \\
2006 & 15 & 3 & 2 \\
2007 & 13 & 6 & 1 \\
2008 & 14 & 6 & 0 \\
2009 & 15 & 5 & 0 \\
2010 & 16 & 4 & 0 \\
U19 & & & \\
2004 & 15 & 2 & 3 \\
2005 & 14 & 1 & 5 \\
2006 & 14 & 4 & 1 \\
2007 & 15 & 4 & 1 \\
2008 & 12 & 3 & 5 \\
2009 & 14 & 3 & 3 \\
2010 & 16 & 2 & 2
\end{tabular}

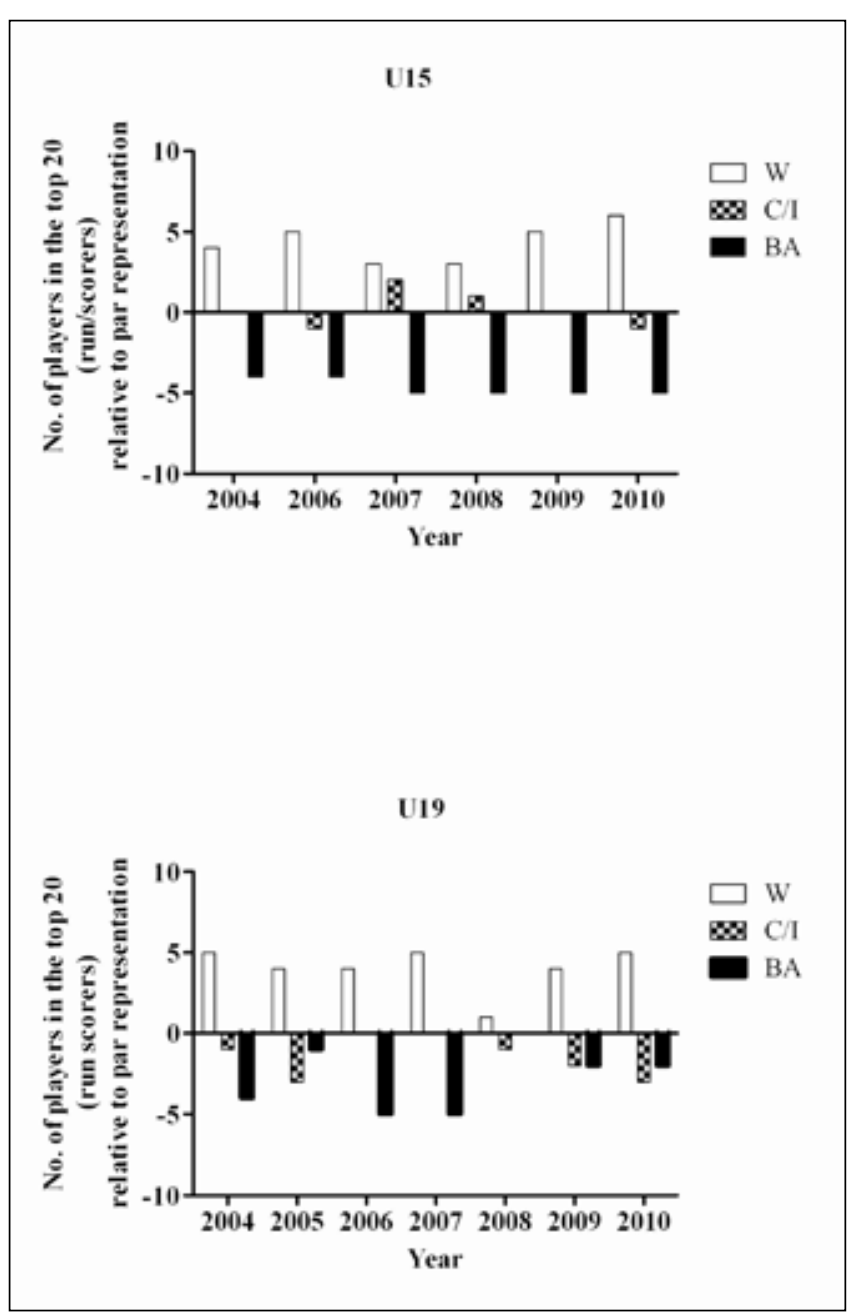

Fig. 2. A representation of the number of players in the top 20 (run scorers) relative to par representation for each racial group. 
Fig. 2 represents the number of players in the top 20 run scorers relative to par representation for each racial group. In the U15s, BA batsmen were well below the par representation level in the top 20 each year. W batsmen were all above par for each year. C/l batsmen reached par in 2004 and 2009, were above par in 2007 and 2008 and below par in 2006 and 2010. For the U19s, BA batsmen were below the par in each year except 2008, where they were equal to par, while the $\mathrm{W}$ batsmen were all above par for each year. $\mathrm{C} / \mathrm{l}$ batsmen reached par in 2006 and 2007 and were below the par in all other years.

\section{Discussion}

The data suggest equal representation of black and W players at junior provincial level in South Africa. This could be seen as a success of the development and transformation process which aims at producing provincial cricketers that are representative of all South Africans. However, the transformation target for junior provincial cricket set by CSA is 6 black players in a 12-man squad. Equal representation is therefore not necessarily a success of transformation but a consequence of the transformation target policy. The decrease in BA players participating in the interprovincial tournaments since 2004 is a concern as one of the aims of CSA is to increase participation of BA at a community and provincial level. ${ }^{4}$ At senior level, BA players have been on the increase since $1996^{1}$ and the current junior results are a drawback to this development and transformation process. CSA has subsequently appointed retired Protea fast bowler Makhaya Ntini as the first cricket development ambassador with the aim of identifying the problems associated with cricket in the historically disadvantaged communities and instituting the appropriate structures for a successful development programme. ${ }^{7}$

Another important aspect of the transformation process is for black players to perform at the highest standards. However, both the U15 and U19 BA batting averages were significantly worse than those of $\mathrm{W}$ batsmen in every year. Furthermore, they were consistently below the par value for representation in the top 20 run scorers in the tournament each year. A further concern is that in 2008, 2009 and 2010 in the U15 group, there were no BA batsmen in the top 20. These batting performance results are similar to senior provincial cricket, where BA batting averages were worse than those of W batsmen in every year between 2000 and 2008 . ${ }^{1}$ The results of the current study indicate that the problem is not in the gap between junior and senior cricket but rather at grass-roots levels.

There are many possible reasons for this. Firstly, advanced visual perceptual processing and visual-motor skills are important for skilled batting performance. ${ }^{8-11}$ There is evidence indicating that in South Africa, BA children (aged between 4 and 7 years) have weaker visual-motor skills than $\mathrm{W}$ children. ${ }^{12}$ This could hinder their batting development. The reason for the poor visual-motor development amongst BA youth could be related to cultural factors. ${ }^{12}$ However, further investigation is required.

Secondly, batting is a skill that has been suggested to require a great deal of commitment, dedication and parental assistance from an early age in order to perfect the numerous number of cricket strokes. ${ }^{13}$ In order to achieve this level of skill, thousands of hours of training are required. ${ }^{14} \mathrm{~A}$ cricketing culture of excellence is therefore important to achieve such skill. Although the BA community has a rich history of cricket dating back more than 150 years, its stronghold has mainly been in the Eastern Cape. ${ }^{15}$ Not surprising that the majority of BA cricketers who have represented the SA national team (Proteas) at test match level come from this region. This culture of excellence is perhaps not as widespread in other areas of South
Africa. A reason for this is that cricket is reported to be only the fourth popular sport among juniors ${ }^{16}$ with soccer being the favoured sport in the black communities. ${ }^{17}$

Thirdly, excellence in batting is achieved more easily through specialised batting courses, readily available training equipment and coaching which are not easily accessible to a large number of BA communities. This argument does not hold for the many BA cricketers who attend some of the best schools in SA and have access to the best coaches, facilities and support, yet they still end up becoming good bowlers. Examples of these are South African fast bowler Makhaya Ntini, Monde Zondeki and Lonwabo Tsotsobe. Finally, the lack of a BA batting icon could also play a role in the minds of young cricketers, who rather aspirer to be a fast bowler like the aforementioned players.

$\mathrm{C} / \mathrm{l}$ batting averages were similar to $\mathrm{W}$ batting averages, indicating the success of transformation in producing skilled $\mathrm{C} / \mathrm{l}$ batsmen. These results closely resemble the senior provincial teams where there were little differences in the batting averages between $\mathrm{C} / \mathrm{I}$ and W batsmen. ${ }^{1}$ However, more recently (2010), C/I had significantly lower batting averages than $\mathrm{W}$ batsmen in both the U15 and U19 groups. This concern is also reflected in the top 20 run scorers for the U19s, where their performance is generally below the par. The W batsmen have performed consistently well between 2004 and 2010.

\section{Recommendations}

The current focus and policies of CSA are broad-based and do not distinguish between batsmen and bowlers or between $\mathrm{C} / \mathrm{l}$ and $\mathrm{BA}$. The data represented in this paper and in a previous published paper1 suggest that perhaps CSA should adapt the current development and transformation policies to increase its focus on improving the performance of BA batsmen.

\section{Conclusion}

BA batting performance at junior provincial level is below standard. Future CSA development and transformation processes should aim at specifically aiding BA batsmen from a young age.

\section{Acknowledgements}

The authors would like to thank all the coaches and coaching managers of the various provinces for their assistance with the classification of players. A special thank you to Dieter Pagel from Cobitech (webcricket.co.za) for supplying the player statistics. A further thank you to Professor Simeon Davies, Naomi Augustyn and Corrie Uys for their assistance.

\section{RefERENCES}

1. Taliep MS. Effectiveness of the cricket transformation process in increasing representation and performance of Black cricketers at provincial level in South Africa. SJSM 2009;21(4):156-162.

2. Smith J, Fredericks G, Basson W, Nyoka M, Tshoma K. Transformation in cricket: Report submitted to the Honourable Minister of Sport and Recreation, Mr N Balfour. http://www.info.gov.za/otherdocs/2002/cricket.pdf (accessed 26 July 2011).

3. UCBSA Presentation Group. Presentation by the United Cricket Board of South Africa to the Parliamentary Portfolio Committee on Sports and Recreation. http://www.pmg.org.za/docs/2002/appendices/020903ucb.ppt (accessed 26 July 2011).

4. Parliamentary Monitoring Group. Cricket SA: Transformation policy: Selection of national cricket team. Transformation background. http://www.pmg. org.za/files/docs/080226csa.pdf (accessed 3 March 2011).

5. Cricket South Africa. KFC Mini Cricket. http://www.cricket.co.za/development programs aspx?id=3 (accessed 26 July 2011)

6. Parliamentary Monitoring Group. Cricket SA: Transformation policy: Selection of national cricket team. http://www.pmg.org.za/report/20080226cricket-sa-transformation-policy-selection-national-cricket-team (accessed 10 February 2011). 
7. Cricket South Africa. Makhaya Ntini backs cricket development. http:// www.cricket.co.za/news article. $a s p x$ ?id=838\&section=news\&subsection= news_all (accessed 7 June 2011).

8. Mann DT, Williams AM, Ward P, Janelle CM. Perceptual-cognitive expertise in sport: a meta-analysis. J Sport Exerc Psychol 2007;29:457-478.

9. Müller S, Abernethy B, Farrow D. How do world-class cricket batsmen anticipate a bowler's intention? Q J Exp Psychol (Colchester) 2006;59:21622186.

10. Taliep MS, St Clair Gibson A, Gray J, et al. Event-related potentials, reaction time, and response selection of skilled and less-skilled cricket batsmen. Perception 2008:37:96-105.

11. Mann DL, Abernethy $B$, Farrow D. Action specificity increases anticipatory performance and the expert advantage in natural interceptive tasks. Acta Psychol (Amst) 2010;135(1):17-23.
12. Dunn M, Loxton $\mathrm{H}$, Naidoo A. Correlations of scores on the developmental test of visual-motor integration and copying test in a South African multiethnic preschool sample. Percep Mot Skills 2006;103(3): 951-958.

13. Goughy K. Where are the black batsmen? http://www.cricketweb.net/blog/ features/15.php (accessed 20 July 2011).

14. Galdwell M. Outliers: The story of success. London: Penguin Books, 2009:35-68.

15. Odendaal A. The story of an African game. Cape Town: David Phillip Publishers, 200:9-55.

16. Cricket South Africa. The annual report 2008/2009. http://www.cricket. co.za/docs/CSA/FULL_REPORT.pdf (accessed 24 July 2011).

17. SouthAfrica.info. Football in South Africa. http://www.southafrica.info/ about/sport/soccer.htm (accessed 22 July 2011). 